\title{
AN ASSESSMENT ON THE COST STRUCTURE OF THE UK AIRPORT INDUSTRY: OWNERSHIP OUTCOMES AND LONG RUN COST ECONOMIES
}

ANNA BOTTASSO

MAURIZIO CONTI

Working paper No. 13 - April 2010 


\title{
An Assessment on the Cost Structure of the UK Airport Industry: Ownership Outcomes and Long Run Cost Economies ${ }^{1}$
}

\author{
Anna BOTTASSO, Maurizio CONTI ${ }^{2}$ \\ University of Genova - Department of Economics
}

This version: April 2010

\begin{abstract}
In this paper we analyze the cost structure of the UK airport industry by estimating a variable cost function for the period 1994-2005. Overall results suggest that the long run average costs curve is Ushaped: it decreases until passenger traffic reaches approximately five millions, it remains flat over the range between five and fourteen million passengers and afterwards it starts to increase. Moreover, our findings provide evidence consistent with the existence of some degree of overcapitalization for the largest regulated airports. Finally, we analyze whether different forms of ownership entail cost differentials across airports and we find that privately owned airports are characterized by lower costs with respect to public and mixed ones, although cost differentials shrank over time as public and mixed airports improved their rate of cost reduction. Main results are robust to unobserved heterogeneity at the airport or market level and to possible endogeneity biases. Possible regulatory and policy implications of these results are also discussed.
\end{abstract}

JEL Codes: L25, L91.

Keywords: scale economies, public ownership, airports.

\footnotetext{
1 The paper benefited of comments from seminar participants at the Public Economics Seminar Series of the Department of Economics and Public Finance "G. Prato" of the University of Torino, IEFE Bocconi, Milano, and $2^{\text {nd }}$ NERI Workshop, Padova. The usual disclaimer applies.

${ }^{2}$ Corresponding author: Maurizio Conti. University of Genova, Department of Economics, Via Vivaldi 5, 16126, Genova, Italy. Tel. ++390102095272. Fax:++390102095497. Email: mconti@economia.unige.it.
} 


\section{Introduction}

During the last twenty years, in the majority of developed economies around the world, the airport sector has experienced important changes regarding ownership structure, governance and regulation. Far from being regarded as public utilities offering aviation services to airlines and passengers, airports are considered as multi-product firms supplying the market a bundled group of services (OFT 2006). Apart from handling passenger traffic, other activities include shipping airfreight (including mail), providing air-taxi services and general aviation, acting as a base for flying training, aircraft maintenance, flight testing and corporate jet activity, and providing a large number of other specialist aviation services. Airports are no longer thought as modal interfaces but as global gateways for tourism and commerce which play an important role in the air transport industry and in the economic and social development of the region they serve. Nowadays airports, independently from their ownership structure, are commercially oriented enterprises with increasing shares of revenues coming from non-aeronautical business.

The evolution of the airport sector over the last decades is linked to the fast growth of the world's airline industry and to the increased competition among airlines fostered by the spreading out of low cost carriers. Institutional and governance changes took place within the context of a wider process of extensive reforms of the utility and transport sectors realized in most OECD countries, characterized by the privatization of public enterprises and by the introduction of economic regulation.

The process of privatization started at the end of the eighties in the UK and was successively pursued by most of developed countries with different degrees of private sector involvement to the ownership/management of airports. The only exception has been the US, where airports have remained mostly municipal or regional-government owned and operated; moreover in Canada the management of government owned airports has been transferred to not-for-profit local airport authorities. Often, though not always, the privatization process has been accompanied by price regulation in order to prevent possible abuse of market power. The form of price regulation varies from country to country, with most being cost-based in principle so that the airport is expected to achieve financial break-even, including a fair return on the capital invested. Some forms of price regulation, such as the Rate of Return regulation may lead to inefficient capital investment and to low incentives to cost reduction; other forms of regulation, such as the price cap, do not regulate profits, but rather prices and set incentives to improve efficiency by allowing airports to benefit from productivity improvements and cost savings; in some countries there is no formal price regulation, but only monitoring of privatized airports.

Privatization and/or commercialization of airports was mainly pursued in order to gain access to private sector financing for capacity expansion and to improve economic efficiency. Several contributes analyze the impact of ownership and institutional form changes on airports performance: among the most recent we mention Oum, Yan and Yu (2008) who analyze a panel of world's major airports. As it is often the case in the literature on the ownership relative efficiency of public utilities (Newbery, 1999), the evidence on this issue is not completely clear cut, although privately owned airports seem to be characterized by somewhat lower costs.

A different strand of the empirical literature has analyzed technical change and productivity growth in the airport sector and has suggested that several factors, others than ownership form, may explain efficiency differentials: size, hub status, degree of market competition, type of regulation, environmental variables are some of the possible efficiency drivers observed in applied works; for an exhaustive survey of this literature we refer to Fung et al. (2008). 
Another subject which has been extensively discussed in the literature is related to airports regulation, both in term of the need for regulation than in term of the identification of pricing schemes able to provide incentives for cost savings, optimal capacity investments and good services quality. The existence of a trade-off between (imperfect) competition and economic regulation has been supported by several authors: both a more effective regulation and a more competitive landscape have been called for by economists and practitioners. Among others, Starkie (2008) and Niemeier (2009) provide excellent discussions on these issues.

In this paper we add to the applied literature by analyzing the cost structure of the UK airport sector observed over the period 1994-2005. As a matter of fact, a detailed analysis of the airport industry cost structure is missing, one of the few exceptions being Pels et al. (2003), who analyze inefficiencies and scale economies on a panel of European airports. ${ }^{3}$ Furthermore, as noted by Oum and $\mathrm{Fu}$ (2008) most of the empirical studies dealing with efficiency and productivity analysis cannot provide reliable measures of scale economies because they often neglect nonaeronautical services outputs, which account on average for more than $40 \%$ of total revenues of an airport, and because they often assume that airports are free to adjust the capital stock even in the short run: such assumption is not realistic within the context of infrastructure sectors and might lead to non-negligible bias in cost economies evaluation.

In our empirical work we estimate a variable cost function conditional on a given level of the capital stock, after taking into account heterogeneity among airports and we discuss cost economies measures derived both for the short and the long run. Moreover, we investigate whether is possible to detect cost differentials between airports characterized by various forms of ownership.

Industry cost structure analysis may be interesting for both regulators and investors, as well for policy makers as it provides useful information necessary for defining regulated prices, for understanding the efficient industry configuration, in term of number and size of operators, and for deciding optimal investment/divestment plans.

In the next section we illustrate the institutional setting of the UK airport sector, we briefly describe previous empirical works and we point out the main issues which feed the actual debate. In section 3 we present the database; in section 4 we show the empirical model and discuss the econometric issues involved. Section 5 comments empirical results and is followed by the conclusions.

\section{Institutional framework}

The 1986 Airports Act has defined the present structure of the UK airport industry by realizing the privatization process announced in the 1985 White Paper on airports policy. At that time nearly all airports were owned by the public sector, either by the British Airport Authority (BAA) or by local governments. BAA had the largest share of the market as it owned seven airports, four in Scotland and three in the London region (Heathrow, Gatwick and Stansted), while the other largest local authority airport was Manchester.

In 1987 all the share capital of BAA were transferred to the private sector by flotation and BAA became BAA plc. Between 1993 and 1999 many local government owned airport assets were also sold. Not all airports have been sold to the private sector or introduced private equity capital: Manchester (UK's fourth largest) belongs to a consortium of local governments in North

\footnotetext{
${ }^{3}$ See also Tolofari et al. (1990) for seven BAA airports, Doganis et al. (1995) for 25 international airports, Salazar de la Cruz (1999) for 16 Spanish airports, Martin et al. (2009) and Abrate and Erbetta (2010) for a panel of Spanish and Italian airports, respectively.
} 
West England and some local governments still retain a majority share in several airports. Furthermore, ownership by unquoted private companies (BAA plc was the exception) has not prevented several of the airports changing hands since they were first transferred to the private sector, some several times (see table 2). The UK airport industry is thus a mixed private-public sector industry but dominated by the private ownership of assets with a strong presence of foreign investors. ${ }^{4}$

At the time of privatization of BAA in 1987 it was assumed that major airports had significant market power linked to their natural monopoly characteristics which called for the need of economic regulation. Airport designated to be regulated after the 1986 Airports Act were Manchester, Heathrow, Gatwick and Stansted. The sector specific regulator is the Civil Aviation Authority (CAA) and price-cap regulation was applied to airports charges with regulatory reviews scheduled every five years and caps set in order to allow for a rate of return consistent with the cost of capital. ${ }^{56}$

This approach is supposed to provide the regulated firm with incentives for efficiency because possible savings in expenditure exceeding those anticipated at the price revision may enhance company profitability. Some of the recent literature (Armstrong et al. 1994) has argued that this approach fails to give adequate incentives to invest because of problems of regulatory commitment, the longevity of sunk investment and the ex-post opportunism that this can give rise to. On the other hand, others (Littlechild 2003) have noted that pressures on regulators have led, in practice, to a convergence of the RPI--X approach with rate-of-return regulation, the latter generally regarded as encouraging overcapitalization and excess capacity. As far as the airport industry is concerned, there is a debate on the choice of revenues to include in the determination of the cap: when both aeronautical and non aeronautical revenues are taken into account (singletill), capacity constrained airports tend to lower aeronautical charges in order to remain under the cap, since more revenue is made on the non aeronautical side. In this situation charges are lowered when efficiency implies they should be raised and airlines will capture location and scarcity rents that could be earned by the airport.

Within the debate about the optimal regulatory policy, the absence of the necessary conditions for airport regulation is also discussed (e.g. Martin and Socorro 2009).

Some authors suggest that the natural monopoly argument for economic regulation is unlikely to hold for airports. In particular, Starkie (2001) suggests that the characteristics of the airport cost structure do not support the need for regulation: when airports operate in a region where the long run marginal cost curve is increasing it is appropriate to set charges above average costs; as the actual regulatory system implies average cost pricing, it might be the case that price regulation may lead to inefficiently low prices. Since there is some (weak) evidence on the existence of long run diseconomies of scale for medium-large airports, ${ }^{7}$ Starkie argues that deregulation

\footnotetext{
${ }^{4}$ When BAA was privatized the government capped the amount of shares that any one shareholder could hold to 15 per cent but, following a ruling by the European Court of Justice that this restriction impeded the free movement of capital in the European Union, it was removed in 2006. Soon afterwards the ECJ's ruling BAA group was taken over by Ferrovial.

${ }^{5}$ The return is calculated taking into account forecasts of air traffic, total revenues (including substantial revenues from commercial activities - single till approach), net operating expenditure after taking into account feasible improvements in efficiency, depreciation of existing capital assets and the proposed capital expenditure plan of the company. The last two components are the constituents of the regulatory asset base (RAB).

${ }^{6}$ The regulated asset base for all three BAA airports (Heatrow, Gatwick and Stansed) was combined for the purposes of judging an allowable return. Starkie (2008) suggested that this had the effect of enabling BAA to leverage its market power at Heathrow in order to support under-performing assets at Stansted. Since 2002 the CAA has changed its policy so that each airport is now considered on a stand-alone basis.

${ }^{7}$ Starkie and Thompson (1985) note that increasing long average costs in the airport industry may be the outcome of
} 
outcome might not necessarily be worse than the regulatory one.

Indeed airports do have market power as the result of rents, mainly associated to land scarcity and locational issues; nevertheless Starkie (2001) argues that airports may be incentivated not to fully exploit their market power because of the existence of complementarities between the demand for aviation services and the demand for concession services. ${ }^{8}$ More in general, possible abuse of market power is prevented by the increasing degree of competition between airports which took place during the last decades as a consequence of the liberalization of European air transports and of the growing importance of Low Cost Carriers. ${ }^{9}$ Furthermore, recent detailed analysis conducted by the CAA and by the UK Competition Commission (2008) reveal that there is significant potential for airport competition in both the London and the North West (Manchester) regions of the UK as a result of the presence of significant overlaps in catchment areas for passenger traffic. Nevertheless the $\mathrm{CC}$ suggested that common ownership of three London airports by BAA was likely to adversely affect competition and in a successive report (2009) ruled BAA would have to divest itself of airports in either Gatwick or Stansted, and either Edinburgh or Glasgow. In December 2009 BAA sold Gatwick to Global Infrastructure Partnership.

BAA Airports performance has been the focus of one of the first works on the UK airport industry conducted by Parker (1999). The author compares BAA airports efficiency scores, obtained with data envelopment techniques, before and after the privatization and does not find any significant difference; moreover his analysis reveals the presence of economies of scale in airport operations but without specifying the relevant output range.

Only recently there has been a renewed interest towards the economic analysis of the UK airport sector. Barros (2008) analyses the technical efficiency of a sample of 27 UK airports observed over the period 2000-2005 by estimating a (translog) stochastic cost frontier which includes a trend variable. Efficiency rankings suggest that the top positions are achieved by small airports, while the most important airports (Gatwick, Heathrow and Manchester) get the weakest positions; moreover costs are found to be increasing over the sample period at a decreasing rate. On the same sample Barros and Managi (2008) compute different Total Factor Productivity (TFP) indices and find that the majority of UK airports did not improve efficiency over the sample period. Moreover, when efficiency scores are sorted by ownership it seems that privately owned airports perform better than publicly owned ones. Similar results are found in another work by Barros and Weber (2009) who estimate Malmquist indices of TFP and show that over the sample period UK airport became less efficient and experienced technological regress; however a clear relationship is not observed between ownership and productivity nor between regulation and productivity. A Data Envelopment Analysis conducted by Assaf (2009) on a sample of 27 airports observed in 2007 suggests that small airports are operating in a increasing returns to scale region, while large ones seem to have reached full capacity and some have exceeded their optimal size.

From the reviewed literature it is evident that main results need to be confirmed by further analysis. In particular we argue that more evidence is needed on the effects of ownership form on airport performance and on the study of the UK industry cost structure; we think the latter deserves more sophisticated analysis given the possible policy implications that can arise.

the complex way in which airports expand.

${ }^{8}$ In 2005 , other operational activities generated about $70 \%$ of the UK BAA airports profits: in the case of Gatwick, profits generated by airport charges were even negative, as in the case of Manchester Airport. This however could also reflect the method used by airports to allocate costs, or it could result from cross subsidies from commercial services to aviation operation under a single till price cap system.

${ }^{9}$ For a recent discussion on the relations between airports and airlines see Oum and $\mathrm{Fu}(2008)$. 


\section{The data}

The dataset used in this study consists of a balanced panel of the major 25 UK airports observed over the period 1994-2005. The main source of data is the statistical series "The UK Airport Industry" published each year by the Centre for the Study of Regulated Industries at the University of Bath. Additional information was sourced from airports accounts and from UK National Statistics, as specified whenever relevant.

The summary statistics reported in Table 1 suggest that in the UK airport industry there is high variability in terms of size. In particular, the size distribution of airports is highly skewed to the right: for example, if we consider the total number of passengers, about $78 \%$ of the observations have a lower value than the mean, and similarly in the case of the work load units. The skewness of the size distribution is driven by the presence of two very large airports, notably Gatwick and, in particular, Heathrow. ${ }^{10}$ In Section 5 we will discuss both how these large size differentials might affect our estimation results and how we have dealt with the issues they rise.

In Table 1 we provide some descriptive statistics on the variables used in the empirical application. Variable costs $(V C)$ are defined as operating costs less depreciation, while the price of non-labor inputs $(o c)$ has been computed as the weighted average of $i$ ) the Construction Output Price Index -COPI- (as a proxy for the price of materials); ii) a price index of water, gas and electricity services and iii) the RPI (as a proxy for the price of other services paid by airports). ${ }^{11}$ The price of labor $(w)$ is obtained by the Annual Survey of Hours and Earnings (ASHE) as the average gross wage paid to employees that live in the local authority where the airport is located. While in most empirical applications (e.g. Barros, 2008) the price of labor is computed as the ratio between labor costs and the number of employees, we believe that this procedure is problematic in the context of the UK airport sector because the sensible differences in outsourcing practices across airports ${ }^{12}$ make it unlikely that unit labor costs reported in the statutory accounts are representative of the "true" price of labor that airports face in their local labor market: its use as a proxy for the price of labor might therefore tend to exacerbate possible measurement errors and endogeneity biases. ${ }^{13} \operatorname{Pax}$ represents the airport total number of passengers; cargo is the airport total tones of cargo (including mail); wlu is the working load units, which is defined as one passenger or $100 \mathrm{~kg}$ of cargo and mail; atm represents the airport air transport movements, defined as landings and takeoffs of aircrafts engaged in the transport of passengers, cargo or mail on commercial terms; com is the revenue from "other operational activities" (deflated with the RPI index), which include apron services, baggage handling, retailing, on-site property rental and car parking .

A more in depth discussion for the definition of the stock of capital and of capital costs is needed. The perpetual inventory method was used to reconstruct a series of the capital stock. In particular, for many airports we have exploited the capital stock revaluations that have occurred

\footnotetext{
${ }^{10}$ There are also two very small airports, Southend and Blackpool.

${ }^{11}$ The weights have been proxied by the cost shares of materials, utility bills and residual services in non-wage costs as reported in BAA airports statutory accounts, respectively.

${ }^{12}$ The major differences in outsourcing practices arise mainly in the case of handling services and air traffic control facilities.

${ }^{13}$ The use of ASHE data is however justified as long as employees of a given airport live in the same local authority where the airport is located and provided that their average wage is fairly well represented by the wage reported in the ASHE. As robustness checks, we also used the median, rather than the average wage reported in the ASHE and the ratio between labour costs and average number of employees of the airport and main results were very similar to those reported in the paper.
} 
over our sample period and we have considered the revaluation year as the baseline. ${ }^{14}$ Whenever a revaluation did not occur we considered 1994 as the baseline year. Capital costs have been computed as the product of the capital stock and the user cost of capital, the latter calculated as the sum of the depreciation rate and the opportunity cost of capital. ${ }^{15}$

As far as the ownership definition is concerned, we have defined an airport as "public" ( $p u b)$ whenever the majority ownership belongs directly or indirectly to one or more municipalities; in turn, an airport has been defined as "mixed" (mix) whenever private investors retain the majority control but local councils hold a substantial minority stake (i.e. bigger than 20-30\%) or when the airport is under public ownership but the management is fully delegated to private investors (e.g. Luton after 1998); finally, an airport that does not belong to either groups is defined as "private" (priv). As of 1994, 12 airports in our sample were publicly owned, against 11 under private ownership and one which is defined as mix; in turn, in 2005, 13 airports were privately owned, against 6 and 5 under public and mixed ownership, respectively. Table 2 reports, for each airport, its ownership status and its changes over the sample period whenever they occurred.

\section{Model specification}

\subsection{Theoretical framework}

Most econometric studies on the airport industry have estimated total cost functions, which are based on the hypothesis that firms minimize total costs in the absence of important fixities in capital inputs; ${ }^{16}$ however, the hypothesis that airports can instantaneously adjust their capital stock may be considered unrealistic. In fact, in the airport industry, the nature of the capital stock is such that it can be considered as a quasi-fixed input in the short run: the capacity of an airport in terms of runaways, terminals, apron areas and other relevant infrastructures is usually built in order to meet the demand which is expected to arise over a long term horizon; moreover, the existence of stringent environmental and planning restrictions limits the possibility of adjusting the capital stock in response to changes in demand. The practice of estimating a total cost function when important inputs cannot be easily adjusted in the short run may generate significant estimation biases in the parameters representing the underlying industry technology and therefore may lead to misleading estimates of cost economies (Shankerman and Nadiri, 1986).

In this paper we allow for the possibility that airports operate off their optimal expansion path as we assume that airports minimize variable costs conditionally on a given level of the capital stock: after estimating a variable cost function we will discuss cost economies measures derived both for the short and the long run. In what follows we briefly show, following Nadiri and Schankerman (1986) and Casarin (2007), how to derive long run measures of economies of scale from the estimated short run variable cost function.

Let us consider a generic variable cost function:

\footnotetext{
${ }^{14}$ We have assumed a constant depreciation rate of $4.5 \%$. The resulting capital stock series was deflated with the COPI index.

${ }^{15}$ The opportunity cost of capital has been proxied by the weighted average cost of capital, which in turn has been derived from the CAA assumptions for the WACC at the relevant price reviews included in sample period. In particular, for airports under public ownership we have simply assumed that their WACC can be proxied by the CAA's assumptions for Manchester Airport, while for private and mix airports we have assumed that their WACC is equal to that assumed for BAA's regulated airports. Nevertheless, the differences in WACC for BAA and Manchseter airports have always been very small. In practice, the price of capital ranges between $12 \%$ and $12.5 \%$.

${ }^{16}$ See, for instance, Barros (2008) and Martin et al. (2009).
} 
$V C=f(w, y, k)$

where $y$ is a vector of outputs, $w$ is a vector of variable input prices and $k$ is the capital stock, which is assumed to be fixed in the short run.

If we define the capital costs as $r k$ (where $r$ is the user cost of capital), we can derive the following short run total cost function:

$S T C=V C+r k$

The equilibrium level for the quasi fixed factor, $k^{*}=h(y, w, r)$, is defined implicitly by the envelope condition as follows: $\partial S T C / \partial k^{*}=\left(\partial V C / \partial k^{*}\right)+r=0$, where $\partial V C / \partial k^{*}$ is the shadow price of capital, which in equilibrium needs to be equal to its market price. After substituting the optimal demand function for capital $\left(k^{*}\right)$ in the short run total cost function $(S T C)$, it is possible to derive the long run total cost function:

$$
L T C=f(y, w, h(y, w, r,))+r * h(y, w, r)=g(y, w, r)
$$

From equation (2) it is possible to derive the elasticity of short run total costs with respect to each output $i$ as a function of the output elasticity of variable costs as:

$\varepsilon_{y_{i}}^{S T C}=\frac{\partial \ln S T C}{\partial \ln y_{i}}=\frac{\partial V C}{\partial y_{i}} \frac{y_{i}}{S T C}=\frac{\partial V C}{\partial y_{i}} \frac{y_{i}}{V C} \frac{V C}{S T C}=\varepsilon_{y_{i}}^{V C} \frac{V C}{S T C}$

The elasticities in equation (4) are based on the hypothesis that the capital stock is fixed in the short run and, as such, they do not provide information on long run elasticities, which are the relevant cost economies measures that should determine long run industry configurations.

Nevertheless, the variable cost function can be used to retrieve long run output elasticities. After differentiating equation (3) and rearranging, it is possible to obtain the following expression for the long run output elasticity:

$\varepsilon_{y_{i}}^{L T C}=\varepsilon_{y_{i}}^{S T C}+(r-z) \frac{k}{S T C} \frac{\partial k^{*}}{\partial y_{i}} \frac{y_{i}}{k}$

where $z=-(\partial V C / \partial k)$ is the shadow price of capital. Equation (5) shows that the long run output elasticity depends on the short run measure, on the difference between the shadow price and the market price of the fixed capital stock and on the sensitivity of the latter to output changes.

If the capital stock is at its long run equilibrium level (i.e. if $k=k^{*}$ ), the shadow and the market price of capital are equal and the long run output elasticity can be written as:

$\varepsilon_{y_{i}}^{L T C}=\varepsilon_{y_{i}}^{S T C}=\varepsilon_{y_{i}}^{V C} \frac{V C}{S T C}=\varepsilon_{y_{i}}^{V C} \frac{V C}{k z+V C}=\varepsilon_{y_{i}}^{V C} \frac{V C}{-\frac{\partial V C}{\partial k} k+V C}=\frac{\varepsilon_{y_{i}}^{V C}}{1-\varepsilon_{k}^{V C}}$

Unlike the common practice in the empirical literature of evaluating the above expression at 
sample levels of the capital stock, equation (6) is a valid measure of long run scale economies only if it is evaluated at $k=k^{* 17}$ In turn, $k^{*}$ can be computed from the envelope condition $\partial S T C / \partial k^{*}=\left(\partial V C / \partial k^{*}\right)+r=0$ using numerical methods if necessary. Most of empirical works that have estimated variable cost functions have neglected the importance of evaluating equation (6) at the long run equilibrium value of the quasi fixed input, thus potentially deriving biased estimates of long run output elasticities and cost economies measures. ${ }^{18}$

On the basis of long run output elasticities it is possible to derive an expression for long run scale economies within the context of a multi-output technology:

$$
\operatorname{LrSE}=\left(\sum_{i} \varepsilon_{y_{i}}^{L T C}\right)^{-1}=\left[\frac{\sum_{i} \varepsilon_{y_{i}}^{V C}}{1-\varepsilon_{k}^{V C}}\right]^{-1}
$$

Moreover it is interesting to measure short run scale economies which are defined as

$$
\operatorname{SrSE}=\left(\sum_{i} \varepsilon_{y_{i}}^{V C}\right)^{-1}
$$

Short run scale economies may be particularly relevant when computed in the case of industries characterized by the presence of significant infrastructures that cannot be easily modified in the short run, like most network industries or the airport and port sectors: within these industries, short run scale economies are sometimes also referred to as economies of density since they measure the impact on variable costs of outputs expansions, given the level of installed capacity.

\subsection{Empirical model}

For the variable cost function in equation (1) we assume a translog functional form. Its main advantage is that it is a flexible form as it is a second order approximation to an unknown function and therefore it does not impose strong a priori restrictions to the underlying production technology, such as a constant elasticity of substitution among inputs, homogeneity or homotethicity. ${ }^{19}$

$$
\begin{aligned}
\ln V C_{i t}= & \alpha+\sum_{j=1}^{J} \beta_{j} \ln p_{j i t}+\sum_{n=1}^{N} \beta_{n} \ln y_{\text {nit }}+1 / 2 \sum_{j=1}^{J} \sum_{s=1}^{J} \beta_{j s} \ln p_{j i t} \ln p_{s i t} \\
& +1 / 2 \sum_{n=1}^{N} \sum_{p=1}^{N} \beta_{n p}\left(\ln y_{n i t} \ln y_{p i t}\right)+\sum_{j=1}^{J} \sum_{n=1}^{N} \beta_{j n} \ln p_{j i t} \ln y_{n i t}+\beta_{k}\left(\ln k_{i t}\right)+ \\
& +1 / 2 \beta_{k k}\left(\ln k_{i t}\right)^{2}+\sum_{j=1}^{J} \beta_{j k}\left(\ln k_{i t} \ln p_{j i t}\right)+\sum_{n=1}^{N} \beta_{n k}\left(\ln k_{i t} \ln y_{n i t}\right)+ \\
& +\beta_{m} \text { mix }_{i t}+\beta_{p} p u b_{i t}+u_{i t}
\end{aligned}
$$

\footnotetext{
${ }^{17}$ If the production technology is homothetic, equation 6 could be correctly evaluated at the sample value of the capital stock, given that the optimal input ratios are constant along a radial output expansion path.

${ }^{18}$ One of the very few papers that have adopted the correct procedure is Casarin (2007) in the case of the gas industry in Argentina and Great Britain.

${ }^{19}$ Recent papers that have adopted a translog functional form in the case of the airport industry are Martin et al. (2009); Pestana Barros (2008) and Oum et al. (2008), among the others.
} 
$V C_{i t}$ denotes variable costs of firm $i$ at time $t$. The vector of variable factor prices, $P$, is defined as $\left[P_{w} ; P_{o c}\right]$, where the subscript $w$ and $o c$ stands for labor and other variables inputs, respectively; $k$ denotes the capital stock; $p u b$ is a dummy variable equal to one for publicly owned airports and zero otherwise; mix is a dummy equal to one for mixed ownership airports and zero otherwise, while $u_{i t}$ is an error term.

The vector of output $Y$ is defined as [wlu, atm, comm.] where wlu denotes the workload units, atm the number of air transport movements and comm the revenue from non aeronautical sources. It is worth noting that, unlike most of the empirical studies on the airport industry, we have included the revenue from non aeronautical charges as an output because of its increasingly importance as a revenue source for many airports. Moreover, as a robustness check, in one model specification we have adopted an even more extended specification of the output vector by including the number of passengers (pax) and the tons of cargo and mail (cargo) instead of the number of workload units: as far as we know, this is one of the very few econometric works on the airport cost structure that adopts a four-outputs specification.

To correspond to a well behaved production structure, the variable cost function must satisfy a set of regularity conditions: it must be linearly homogeneous, non-decreasing, concave and symmetric in factor prices; non-decreasing in output; non-increasing and convex in the fixed input. In particular, the properties of linear homogeneity and symmetry in factor prices are imposed prior to estimation; ${ }^{20}$ in turn, concavity in input prices of the cost function is verified if the Hessian is a negative semi-definite matrix, while monotonicity in factor prices requires that costs rise as factor prices rise; finally, monotonicity in output requires positive marginal costs. Both monotonicity and concavity conditions are checked after estimation.

Applying Sheppard's Lemma to equation (9), it is possible to derive the following equation:

$$
\frac{\partial \ln V C}{\partial \ln p_{i}}=\frac{\partial V C}{\partial p_{i}} \frac{p_{i}}{V C_{i}}=\frac{p_{i} X_{i}}{V C_{i}}=S_{i}
$$

Where $S_{\mathrm{i}}$ is the share of input $i$ in total costs and $X_{\mathrm{i}}$ is the optimal conditional demand of input $i$. After appending an error term to the cost shares, the system made up of the cost function and the labor share (the "other variable inputs" share equation has to be dropped to avoid the singularity problem stemming from the fact that the shares add up to one), can be estimated, after imposing the restrictions suggested by economic theory, with an efficient iterative seemingly unrelated regression procedure, which allows for cross equation correlation in the disturbance terms.

\subsection{Econometric issues}

The estimation of the system of equations (9) and (10) rises a set of important econometric issues. First, the panel data nature of the dataset could be exploited by letting the disturbance

\footnotetext{
${ }^{20}$ Homogeneity can be imposed by normalizing the dependent variable and factor prices with the price of one of the inputs: we normalized for the price of other costs (this normalization procedure is equivalent to impose the following restrictions: $\left.\sum_{j=1}^{J} \beta_{j}=1 ; \sum_{j=1}^{J} \beta_{j s}=0 ; \sum_{j=1}^{J} \beta_{j n}=0 ; \sum_{j=1}^{J} \beta_{j k}=0\right)$, thus reducing the components of the $P$ vector to one. Symmetry of the cost function is imposed by assuming that $\beta_{j s}=\beta_{s j}$ and $\beta_{n p}=\beta_{p n}$ before estimation.
} 
term in the cost function to be specified as the sum of two independent components: $u_{i t}=e_{i}+v_{\mathrm{it}}$, where $e_{i t}$ reflects a time invariant airport specific component, while $v_{i t}$ is an IID random component with zero mean, uncorrelated with itself, homosckedastic and uncorrelated with the regressors. If we allow $e_{i}$ to be correlated with the regressors, we could estimate the system with a SURE-fixed effects technique, by inserting a set of airport-specific dummy variables in the cost function. The advantage of this specification is that it avoids parameter biases arising from possible correlation between unobserved individual airport heterogeneity and the regressors. However, one pitfall of this fixed effects approach is that, when some of the explanatory variables have very little within group variability, it may yield imprecise (often downwards biased) parameter estimates: unfortunately, this is exactly what happens in our case, where the within variation of outputs is very small, if compared to the between variation. ${ }^{21}$ Therefore, we decided to deal with unobserved heterogeneity in other ways.

It seems reasonable to assume that some unobserved heterogeneity is linked to regional and market level characteristics. To this purpose we divided the airports in our sample into six different geographic markets, partly on the basis of considerations developed by both the Office of Fair Trade and the Competition Commission in the recent BAA case, and partly on our assessment based on distances between airports (two hours driving time). The markets identified by the Competition Commission ${ }^{22}$ and the OFT studies were the London area and Scotland. The first market includes Heathrow, Gatwick, Stansted, London City, Luton, and Southampton, to which we have added the small airports of Southend and Norwich; the Scottish market is made up of Glasgow, Edinburgh and Aberdeen. We have identified four additional markets, namely, North of England (Newcastle and Durham-Tesside); Centre (Manchester, Humberside, Nottingham, Birmingham, Blackpool, Leeds and Liverpool); South East (Bournemouth, Cardiff, Bristol and Exeter) plus Northern Ireland (Belfast). Alternatively we considered the twelve UK NUTS level 1 regions where the airports are located as proxies for the regional markets where airports operate.

In order to take into account regional and/or market level heterogeneity we specify the error term in the cost function equation as $u_{i t}=\delta_{j t}+v_{i t}$, where $\delta_{j t}$ is a full set of market-year fixed effects that proxy for time varying unobserved heterogeneity in the geographic market $j$ where the airports operate. The inclusion of these market-year dummies controls for shocks that may hit the markets where the airports are located, as well as for differences in the economic environment they face: as a result, they should capture both the regional specific business cycles and the (changes in) intensity of competition in each particular market (with the associated feedback effects on airport charges and, therefore, outputs), or in other locational related variables (e.g. population density, transport infrastructure, income wealth of the local population, economic development and so forth). As a robustness check, the market and year dummies have been also included in the cost function in a non-interacted way. In other words, the error term was specified as $u_{i t}=\delta_{j}+\varphi_{t}+v_{i t}$. Furthermore, we have also checked that the results are not sensitive to the inclusion of region-year (rather than market-year) fixed effects: the advantage of using region-year fixed effects is that we should better capture local unobserved heterogeneity, given that we have twelve regions against six markets.

Another important source of unobserved heterogeneity is that associated to managerial ability: in

\footnotetext{
${ }^{21}$ If some explanatory variables are well explained by a set of firm specific fixed effects, the fixed effects estimator is unlikely to provide precise estimates. We therefore regressed each output on a set of airport dummy variables and the adjusted $\mathrm{R}^{2}$ turned out to be very close to one in the case of pax, atm, wlu and cargo.

${ }^{22} \mathrm{We}$ can note that in its final report, the Competition Commission choose not to define rigid geographic markets in the case of the UK airport sector.
} 
order to control for it and to take into account the impact on costs of changes in the corporate control of each airport, we have created a set of "group" specific dummy variables. For each airport that never shared a common owner with any other airport in the sample and that did not change owner over the sample period (e.g. Exeter Airport), we create a dummy which works essentially as an individual airport fixed effect; for those airports that did not share a common owner with any other airport in the sample but that did change owner over the sample period (independently on the type of owner, i.e. it might well be a "private" to "private" change), we create as many dummies as the number of owners; finally, for those airports that shared a common owner we create a dummy variable equal to one for all airports sharing the same owner and zero otherwise (this is the case, for example, of airports belonging to TBI, BAA, Manchester or National Express). ${ }^{23}$

One version of equation (9) has been estimated after including the group specific fixed effects: this is equivalent to assume that the error term is specified as $u_{i t}=\delta_{j t}+\psi_{g}+v_{i t}$, where $\psi_{g}$ represents the group specific dummy variables. The inclusion of $\psi_{g}$ in the cost function should make our results robust to the existence of possible unobserved heterogeneity associated to managerial ability and may also pick up possible correlations in the residuals of airports that are under common ownership. Furthermore, given the way the group dummies have been built, they should be able to capture some of the unobserved heterogeneity that may drive the acquisition of a particular airport (e.g. a bad managerial performance): as a result, the inclusion of the $\psi_{g}$ should be another way, complementary to IV estimation (see Section 5), to verify whether our estimates of the effects of ownership form on costs are robust to selection issues.

Another important econometric problem (often neglected in most empirical studies that estimate cost functions) that has to be addressed is the possible existence of heterosckedasticity due to the large size differentials that characterize the UK airport sector. To deal with this problem we have estimated the SURE system assuming that the error term in the cost function is specified as $u_{i t}=\delta_{j t}+e_{i}+v_{i t}$, where we assume, as in Bhattacharyya et al. (1997), that $v_{i t}$, is IID $\sim\left(0, \sigma_{\mathrm{v}}^{2}\right)$, $e_{i} \sim\left(0, \sigma_{\mathrm{ei}}{ }^{2}\right)$; and that they are uncorrelated with each other, with the error term in the labour share equation and with the regressors. ${ }^{24}$ The advantage of this "Random Effects SURE" approach is that it allows the airport specific error term to be heterosckedastic; furthermore, if the $e_{i}$ were present but not taken into account, they would eventually show up as serial correlation in the error term, potentially invalidating statistical inference. ${ }^{25}$

\footnotetext{
${ }^{23}$ In total, we have created 26 group dummy variables.

${ }^{24}$ Although we refer to Bhattacharyya et al. (1997) for a detailed explanation, we can briefly describe the estimation strategy as follows. First, one estimates the SURE model in equations (9) and (10) after a within transformation of the cost function and retrieves the mean squared error of the cost function residuals as an unbiased estimate of $\sigma_{\mathrm{v}}{ }^{2}$ then the system is re-estimated without the within transformation to get the cost function residuals $\hat{u}_{i t}$ The variance of the cost function residual $\lambda_{i}^{2}$ is computed as the mean squared error of the cost function residuals as $\hat{\lambda}^{2}-\sum \hat{u}_{i t}^{2} / T$. Since $\lambda_{i}^{2}=\sigma_{v}^{2}+\sigma_{e i}^{2}$, it is possible to estimate $\sigma_{e i}^{2}$ as $\hat{\sigma}_{e i}^{2}=\hat{\lambda}_{i}^{2}-\hat{\sigma}_{v}^{2}$ Finally, one computes the transformation parameter $\theta_{i}$ as $\theta_{i}=1-\sigma_{v} / \sqrt[2]{\sigma_{v}^{2}+T \sigma_{e i}^{2}}$. It is then possible to transform the cost function by subtracting to each variable a fraction $\theta_{\mathrm{i}}$ of its group mean and estimate the system by iterated SURE on the pooled sample, yielding efficient parameter estimates.

${ }^{25}$ Serial correlation in the cost function error term could also arise for reasons not directly related to the omission of the airport specific random effect. Therefore, as a robustenss check, we have assumed that the error terms in both the cost function and share equations follow an AR(1) process; we have then applied a Cochrane-Orcutt transformation to the data and, finally, we have estimated equations (9) and (10) with an iterated SURE technique on the transformed data, as in Sung and Gorth (2000). The econometric estimates largely confirm our main results (both as far as the impact of ownership and the existence and magnitude of scale economies are concerned), thus suggesting
} 
A final econometric issue that needs to be addressed is the possibility that both output variables and ownership status may be endogenous to the model. It is important to recognize that possible endogeneity issues stemming from omitted variables at the group level (such as managerial ability) or at the market-year level are controlled for in (some of) our regression specifications. However, as robustness checks, we have also estimated the system with an instrumental variable technique (3SLS).

\section{Empirical results}

In this section we discuss empirical results obtained by estimating the system of equations (9) and (19) with different econometric techniques.

First, we examine the validity of the restricted equilibrium framework using the test proposed by Shankerman and Nadiri (1986), to which we refer for an in depth discussion of the punctual procedures we have followed for its implementation. ${ }^{26}$ The application of this test leads us to reject, at whatever confidence level, the null hypothesis that UK airports were operating at their long run equilibrium, which in turn suggests that previous papers that have estimated total cost functions in the case of the UK airport sector might have been misspecified. On the basis of this result we have computed the equilibrium levels of the capital stock $\left(K^{*}\right)$ as explained in Section 4.1. When we compare the optimal equilibrium levels with their sample counterparts, computed at different percentiles of the size distribution, we find some empirical evidence consistent with the presence of a slight degree of undercapitalization for small-medium airports. On the other hand, largest airports tend to display a ratio $K / K^{*}$ higher than one which suggests the presence of overcapitalization; in particular, airports at the $75^{\text {th }}$ percentile of the size distribution show a moderate amount of overcapitalization which becomes more evident starting at the 90 th percentile (i.e. about 20 million passengers). Recalling that largest UK airports (Heathrow, Gatwick, Stansted and Manchester) are the only ones designated for price regulation, our findings may support the idea that the regulatory approach adopted in the sector might have provided incentives for excess capacity. Alternatively, some authors (Starkie, 2008) suggest that some degree of overinvestment might be the result of largest operators with significant market power (i.e. BAA) trying to preempt entry in the relevant geographic market through investment in excess capacity.

We then checked the regularity conditions of the cost function: in all models fitted cost shares are non-negative at each data point; marginal costs are non-negative for about 85 per cent of the sample while the concavity requirements for input prices are satisfied for all observations. Moreover, we tested whether the technology underlying the estimated variable cost functions is homothetic and a Wald test statistics leads us to reject this hypothesis at conventional confidence

that serial correlation is probably not a major concern in our empirical application (results are available from the authors upon request).

${ }^{26}$ Shankerman and Nadiri (1986) note that if firms are in long run equilibrium, the rental price of the quasi-fixed capital stock is expected to be equal to its shadow price. Using the envelope condition discussed in section 4.1, one might derive an equation which implicitely defines the long run demand for capital. The implementation of the test requires the estimation of the system given by equations (9) and (10) together with the equation for the demand for capital. The estimation of this system yields consistent and efficient estimates insofar as firms are operating at their long run equilibrium path; otherwise, the estimates would be inconsistent. In turn, the estimation of equations (9) and (10) provides consistent estimates even when firms are off their long run equilibrium path (although they would be inefficient if firms were operating at the long run equilibrium). An Hausman type test is then constructed comparing parameters obtained from the estimation of equations (9) and (10) with those obtained from the estimation of the same equations plus the long run demand for capital. 
levels for all model specifications: this result further supports our empirical strategy of evaluating long run cost economies measures (equation (7)) at long run theoretical capital levels rather than at sample values.

It is worth recalling that all results are robust to the inclusion of a set of market (or region)-year dummy variables that can capture time varying unobserved heterogeneity at the regional and market level linked to the presence of low cost airlines, different tourism flows and regional specific shocks or business cycles, differences in the competition intensity, in the transport infrastructure endowments, in population densities and in the rate of technical change, etc. Furthermore, supposing that some municipalities in different regions tried to help their local airport to attract low-cost airlines (e.g. by directly performing some marketing activity), it is possible that subsidised airports might display lower costs that should however be captured by the market-year dummies. ${ }^{27}$ Finally, our results are also robust to the inclusion of additional control variables such as the percentage of international passengers and the Herfindhal Index of concentration in the geographic market where airports operate: ${ }^{28}$ however, given that these variables turned out to be often insignificant, we have dropped them from the final specifications reported in Tables 3 and 4.

All explanatory variables have been normalized by their sample medians and therefore first order coefficients can be interpreted as variable cost elasticities evaluated at the sample median. Parameter estimates of first order coefficients reported in Table 3 and 4 show a similar pattern across different model specifications. In particular, the wage elasticity is significantly positive and its magnitude is very similar to the sample median labor share as expected from economic theory. In turn, variable cost elasticities with respect to the different output measures are positive and statistically significant as expected and the variable cost elasticity with respect to capital is negative in six out of seven model specifications suggesting that, at the sample median, capital additions tend to reduce variable costs.

Output variables have been treated as exogenous; nevertheless, although we control for unobserved characteristics at the market-year level, endogeneity issues may still arise: for example, if a negative shock to costs is transferred to customers through higher airport charges, then there might be a reduction in output levels so that the latter would be correlated with the error term. Even if this issue has always been neglected in the previous empirical literature in the case of the airport sector, we tackled this problem: in particular, we have estimated the system of equations (9) and (10) with 3SLS, after instrumenting output variables (and their interactions) with their lagged values, population in the NUTS 1 region where the airport is located and its interactions with exogenous variables. Parameter estimates reported in Table 3 as Model 2 are very similar to those reported in Model 1, when output variables have not been instrumented.

In order to tackle the issue of the impact of ownership form on airports' cost performance, all estimated models include a dummy variable (priv) which is equal to one for airports under private control. The excluded group includes both public and mixed ownership airports as we could not reject the null hypothesis of the existence of significant cost differentials between those two groups. Estimates show that the ownership dummy variable is significantly negative in all model specifications with a magnitude that ranges between -0.11 and -0.21 , thus suggesting that privately owned airports exhibit lower variable costs. This result is robust to possible problems stemming from reverse causality issues, as in Model 5 the ownership form has been

\footnotetext{
${ }^{27} \mathrm{All}$ results are robust to the inclusion of region-year dummies as an alternative to market-year dummies as well as to the inclusion of market dummies and year dummies separately. Estimation results are available upon request.

${ }^{28}$ The Herfindhal index in the market $j$ was built as $H_{J}=\sum\left(S_{i}\right)^{2}$, where $S_{i}$ is the share of passengers in market $j$ served by airport $i$.
} 
treated as endogenous to the model and instrumented. In particular, following the two-step approach pioneered by Heckman (1978), we have estimated a reduced form equation which models the probability for an airport of being "private" as of time $t$. In particular, we let this probability to depend on previous profitability $(\Pi)$, value added growth in the region (NUTS 1 ) where the airport is located $(V A G)$ and on a set of year dummies:

$p_{i t}=\gamma_{1} \Pi_{i t-1}+\gamma_{2} V A G_{i t}+\varphi_{t}+\xi_{i t}$

Equation (11) was estimated by $\operatorname{OLS}^{29}$ and the predicted probability $\widehat{p_{i t}}$ was used as an instrument for the ownership dummy priv using a 3SLS procedure. The exclusion restrictions underlying this identification strategy are that lagged airport profitability and regional growth of value added are not valid explanatory variables for the translog variable cost function. ${ }^{30}$ The existence of cost differentials associated with private ownership is confirmed when we estimate a specification (Model 6) including a set of group dummies ${ }^{31}$ which take into account unobserved heterogeneity linked to managerial ability, changes in majority control, different access to the capital markets, etc. As an additional robustness check we have alternatively inserted in the cost function a full set of airport individual dummy variables. With this approach ownership changes that occurred over the sample period allow us to identify the effect of ownership on airport costs: in other words we can take into account the possibility that the "ownership status" of an airport is not random, but potentially correlated with time-invariant airport specific unobserved characteristics that, if not controlled for, could bias the effects of ownership form on costs. ${ }^{32}$ Reassuringly, when we control for airport fixed effects the dummy priv retains its sign and statistical significance, although its magnitude falls to $-0.08 .^{33}$

Previous empirical evidence on the effect of institutional factors on airport performance is scant; furthermore, a potential drawback of this literature is that the issue of possible endogeneity of ownership form has been completely neglected. However, our results are consistent with those reported in Barros and Marques (2008) on a panel of European airports and in Oum et al. (2008) who estimate a Bayesian stochastic cost frontier on a panel of world major airports and found that privately owned airports, as well as those managed by independent authorities, are more efficient than those with various forms of government ownership and management combinations. As we noted in the Data Section, the UK airport sector is characterized by large size differentials, which may create heterosckedasticity problems and outliers or influential observations issues. In order to check whether our results are influenced by the presence of influential observations, we have estimated all models after dropping the two smallest airports in terms of passengers (Southend and Blackpool) or the two largest (Heathrow and Gatwick), and our main results were confirmed. Moreover, we have dealt with possible heterosckedasticity problems in Model 7, which is a random effects model estimated with a SURE technique as proposed by Bhattacharyya et al. (1997) that allows the individual error term to be

\footnotetext{
${ }^{29}$ Estimates are available from the authors upon request.

${ }^{30} \mathrm{We}$ tested the validity of these exclusion restrictions by augmenting the original model with both lagged airport profitability and regional growth of value added which never turned out to be statistically significant.

${ }^{31}$ For details on the construction of the group dummies see the Section 3.

${ }^{32}$ In section 4.3 we decided not to rely on the fixed effetcs approach as far as scale economies estimation is concerned because the insufficient within group variation of output variables would not allow us to measure their elasticities with enough precision.

${ }^{33}$ All other variables retain their sign and statistical significance. As expected, the magnitude of the output variables coefficients is quite lower than that we have found in the non-fixed effects approaches. Estimates are available from the authors upon request.
} 
heterosckedastic, as explained in Section 4.3: estimates reported in Table 4 confirm main results. As a further robustness check we have augmented the translog variable cost function in equation (9) with a time trend, its square and its interactions with outputs, factor prices and capital stock. This alternative specification (Model 3) is aimed to model the impact of technological progress in the UK airport sector; in particular, it allows for the possibility that technical change is scale augmenting and non-neutral with respect to inputs. Although some of the trend related variables are imprecisely estimated, a test on the joint significance of all regressors that include the trend variable leads us to reject the null hypothesis that they are jointly equal to zero at conventional confidence level. ${ }^{34}$ Following Caves et al. (1981), we measure technical change as the common rate at which all inputs can be decreased over time while keeping outputs fixed (trend rate of cost reduction): $T C=-(\partial \ln V C / t) /(1-\partial \ln V C / \ln k) .{ }^{35}$ Estimates reported in Table 5 for the median airport in each year ${ }^{36}$ show that technical change has been significantly positive in all years with an average rate of about 2 per cent: in particular, technical change declined from 2.8 per cent per year to 1.5 per cent in the first five years of the sample period while it stayed about constant (with an average rate of 1.9 per cent), albeit with minor fluctuations, in the remaining years.

We have also allowed the rate of technical change to take on different values depending on airports' ownership status by interacting the time trend and its square with the priv dummy variable: in this way we can also investigate how cost differentials associated to ownership may have changed over time. The econometric estimates (not shown) suggest that technical change in the case of private airports fell relatively to the public and mix ones, while the dummy priv remains negative. ${ }^{37}$ In particular, as data reported in Table 5 suggest, the average rate of cost reduction for private airports declined from 3.3 per cent to about 0.8 per cent (with an average rate of about 1.6 per cent over the sample period); in turn, in the case of public and mixed airports, the rate of technical change went up from 2 to 4 per cent, with an average rate of about 2.6 per cent over the sample period. ${ }^{38}$ Our econometric estimates indicate that in the early part of the sample period the average cost advantage of private airports might have been as high as twenty per cent but also that the differential shrank over the sample period to about ten per cent. The time pattern in the private/public-mix airport cost differential is confirmed if we include in the model a full set of airport fixed effects to take into account unobserved heterogeneity at the airport level (that might have driven changes in ownership form); however such cost differential turns out to be very small and not statistically significant in the last two years of the sample.

As a final robustness check we have considered a more general model with airports fixed effects where we separately identify three ownership groups, namely private, mixed and public and we estimate a similar model to that reported in equation (9) after including two dummies ( $p u b$ and mix) and their interaction with trend and trend square. The results confirm again that the performance of private airports deteriorated over the sample period, while that of mixed and, especially, public airports improved over time. ${ }^{39}$ The empirical estimates show that both mixed

\footnotetext{
${ }^{34} \mathrm{We}$ also tested the hypothesis that technical change was neutral and we had to reject it at conventional sign. levels.

${ }^{35}$ The values of TC have been computed using the long run equilibrium values of the capital stock.

${ }^{36}$ Our technical change figures are referred to the median airport in each year: in other words, all variables that enter the elasticities in the technical change formula are evaluated at their median value for each year. In this way we are able to account for the changes that occurred over the sample period in those variables that may affect technical change, namely outputs, input prices and capital stock.

${ }^{37}$ Interaction terms between trend and trend square with the dummy priv are jointly significant (the $\mathrm{p}$ val. is 0.09 ).

${ }^{38}$ The decline in the rate of cost reduction for private airports and the corresponding increase in the case of public and mixed ones is broadly confirmed if we include in the cost function a full set of airport fixed effects.

${ }^{39} \mathrm{An} F$ tests suggests that we cannot reject the null hypothesis that the interactions of trend and trend square with the dummy mix $(p u b b)$ are jointly equal to zero at the $5 \%(1 \%)$ level of significance. Full estimation results are available
} 
and public airports had statistically significant higher costs in the early part of the sample but that cost differentials progressively shrank and became null for the last years.

These results imply that, although, on average, over the period 1994-2005 UK private airports had displayed lower costs, their relative cost advantage has shrunk over time with respect to both public and mixed airports, suggesting that the latter may have better succeeded in cutting costs over the sample period. Our findings are not consistent with those reported in Barros (2008), Barros and Managi (2008) and Barro and Weber (2009); nevertheless the discrepancy may be due to the different methodologies adopted and the sample period considered in this paper so that appropriate comparisons cannot be conducted.

\subsection{Cost economies}

Parameter estimates for the variable cost function allow us to derive long run cost economies measures computed as in equation (7). All findings, obtained from the estimation of different versions of our baseline model, are robust to the exclusion of either the two largest airports (Heathrow and Gatwick) or the two smallest (Southend and Blackpool).

Table 6 reports punctual values for long run scale economies evaluated at different percentiles obtained by keeping the labour price fixed at the sample median of the entire sample and letting outputs and the optimal long run capital stock to vary across different percentiles. In all estimated models economies of scale tend to gradually decrease with the scale of operations, with values ranging on average (across models) between 2.08 at the $10^{\text {th }}$ percentile and 0.84 at the $90^{\text {th }}$ : in particular, for the median airport, scale economies are equal to about 1.35 , thus implying that a one per cent proportional increase in all outputs would lead total costs to rise by 0.74 per cent in the long run. Overall results suggest the presence of scale economies at least up to the $75^{\text {th }}$ percentile (which corresponds to an airport with about 5.6 million passengers, 83000 atm and 6.5 million $w l u)^{40}$, while largest airports tend to experience diseconomies of scale starting on average between the $80^{\text {th }}$ and the $90^{\text {th }}$ percentile, i.e. for an airport with about 14 million passengers, $148000 \mathrm{~atm}$ and 15 million $\mathrm{wlu}^{41}$

In order to ensure that the values used in scale economies computations better reflect the characteristics of our sample, ${ }^{42}$ we identify the $i^{\text {th }}$ percentile airport with respect to output $j$ and use that company's capital stock and values for other outputs in the formula for scale economies. ${ }^{43}$ Scale economies values reported in Table 8 are broadly consistent with the overall pattern shown in Table 7.

As an additional robustness check we evaluated long run scale economies after splitting the sample into three size groups according to either $a t m$, wlu or $p a x ;{ }^{44}$ for each group we have then taken the median values for all variables involved in the computation. Again, results confirm that

\footnotetext{
from the authors upon request.

${ }^{40}$ Examples of such airports are Newcastle and Nottingham.

${ }^{41}$ Manchester, Stansted, Gatwick and Heathrow are those airports operating at output levels characterized by diseconomies of scale.

${ }^{42}$ Scale economies values reported in Table 6 at the $i^{\text {th }}$ percentile were computed by substituting in the relevant formula the $i^{\text {th }}$ percentile value for each variable excluding labor price for which we always substituted the sample median value.

${ }^{43}$ For example, in the first row of Table 8 we identified the airport corresponding to the $i^{\text {th }}$ percentile of $\mathrm{atm}$ and, for computing scale economies, we have employed that airport's values of capital stock, wlu and pax, and not their corresponding percentiles. The same approach has been followed after identifying the airport corresponding to the $i^{\text {th }}$ percentile of pax and wlu.

${ }^{44}$ The cut-offs points defining the three size categories are 30000 and 100000 atm; 1.5 and 6 million wlu and, finally, 2 and 10 million pax.
} 
scale economies decrease alongside the size distribution and suggest that largest airports are operating under a diseconomies of scale regime.

A similar picture is provided by the analysis of short run scale economies as shown in Table 7 . Short run cost economies, in the airport industry, can be interpreted as economies of density: our results thus suggest that, for a given level of the capital stock, a proportional increase in all outputs is associated to a reduction in average variable costs for airports operating up to a level of outputs between the $50^{\text {th }}$ and the $75^{\text {th }}$ percentile of the size distribution. In particular, if compared with long run measures, short run scale economies tend to fall more rapidly with size so that at the $75^{\text {th }}$ percentile we cannot reject the null hypothesis of constant scale economies in five out of seven estimated models. Furthermore, diseconomies of scale observed for largest airports are on average less pronounced in the short than in the long run: this result is consistent with the finding of excess capacity for largest operators (Friedlaender et al., 1993).

As far as the previous literature is concerned, there is scant empirical evidence on the cost structure of the airport industry. One of the few exceptions for the UK case is Tolofari et al. (1990) that estimate a translog variable cost function for the seven BAA airports observed over the period 1979-87 and find evidence of economies of scale up to 20.3 million wlu: this finding is broadly consistent with our result which however is based on a larger sample in a later period. Other studies, mostly conducted on European or US samples, find evidence of scale economies for small airports while larger airports are often found to operate under diseconomies of scale. Among them we mention Martin et al. (2009) who found, by estimating a total cost function for a panel of Spanish airports, unexhausted scale economies at any level of output although a possible drawback of this study is the assumption that the capital stock is freely adjustable and that commercial revenues are neglected; Salazar de la Cruz (1999) who applied non parametric methods to a panel of Spanish airports and find that average costs are U-shaped as they decrease up to 3.5 million passengers and then increase from 12.5 million; Pels et al. (2003) who estimate two separate frontiers for the production of passengers and air transport movements for a sample of European airports and find that the average airport (12.5 million passengers and $150000 \mathrm{~atm}$ ) operates in a constant returns to scale region in the production of atm and under increasing returns to scale in the production of passenger movements; moreover they found that scale elasticity is decreasing in the number of passengers. The analysis of this short literature review suggests that any comparisons requires the use of much caution in interpreting the results because of non negligible differences in the methodological approaches, as well as sample and period of observation.

The analysis of the cost structure of the airport industry may provide useful insights to the debate on the regulation of the sector. Our findings suggest that the largest UK airports operate in a region of diseconomies of scale so that long run marginal costs are higher than average costs: in this case, it is reasonable to expect that large airports set charges above average costs. Since the regulatory regime applied by the CAA is in practice based on a form of average cost pricing, it might be the case, ceteris paribus, that regulated charges are inefficiently low so that they may not provide the correct economic signals that would ensure allocative efficiency. Another implication of our results on the price regulation of the airport industry is relative to the determination of the $X$ factor in the price cap formula. Since the productivity offset $X$ required by the regulator at the price review should include a correction for the presence of non-constant returns to scale (Bernstein and Sappington, 1999), our results suggest that if the regulator is forecasting output growth over the regulatory period, she should proportionally reduce expected productivity improvements, given that UK regulated airports are operating in a region of diseconomies of scale. Finally, our analysis may offer some useful insights as far as the optimal industry configuration is concerned; for example, the existence of significant scale economies at 
least up to five million passengers should be considered by policymakers when required to decide on the construction of new airports that are unlikely to get to the efficient scale of operations: although the construction of new airports can lead to more competition in the sector, thus increasing consumer welfare, the presence of non negligible scale economies for smaller airports may push up average costs, potentially leading to inefficient entry, thus harming consumer welfare.

Turning to the discussion on the existence of biased investment incentives in the UK airport industry, our findings of overcapitalization for largest airports might support the view that the price cap regime as implemented in the UK airport sector has assumed common features with rate of return regulation that might have encouraged some degree of gold plating and overcapitalization.

\section{Conclusions}

In this study we estimate a translog variable cost function for a sample of 25 UK airports observed over the period 1994-2005. To the best of our knowledge, this is the first attempt to provide a detailed picture of the UK airport industry cost structure; moreover, we have conducted an in depth investigation on the possible effects of ownership form on airport performance. The choice of estimating a variable cost function conditional on a given stock of capital reflects the assumption that airports are not free to adjust capital inputs in the short run. Although the quasi-fixed nature of the capital stock has been neglected in the previous literature, our results suggest that observed airports are not operating along their long run equilibrium path, thus casting some doubts on the reliability of empirical findings based on the assumption that airports can freely adjust all inputs; in particular largest airports in the sample show a certain degree of overcapitalization.

Our results suggest that over the period privately owned airports exhibit lower variable costs with respect to their public or mixed ownership counterparts: this finding is robust to the presence of unobserved heterogeneity at the airport and market level and to the possible existence of ownership endogeneity issues. Moreover, we find a positive rate of cost reduction in the industry and ownership cost differentials shrinking over the sample period. This pattern might be explained by considering that, in the early part of the sample, public and mixed ownership airports were probably characterized by a relatively higher level of X-inefficiency, perhaps for the stronger agency problems associated to public ownership. However, our empirical findings also suggest that the cost advantage of private airports started to fall only at end of the 1990s, exactly when the competition in the UK airport industry -associated to the intensification of competition in the airline industry for the large scale entry into the sector of low-cost airlines- also increased. But, as noted in Hart's (1983) seminal paper, an increase in product market competition is likely to foster productivity growth precisely for those firms more likely to suffer from significant agency problems. ${ }^{45}$

Empirical estimates on scale economies suggest that the long run average cost curve is Ushaped: average costs decrease until passenger traffic reaches approximately five millions; they remain flat in the range between five and fourteen million passengers and then start to rise. This finding is based on the estimation of models characterized by a rich output specification and holds across different models and estimation strategies.

\footnotetext{
${ }^{45}$ Another implication of Hart's (1983) paper is the use of debt as a discipline device in firms with agency problems: the increase in the rate of cost reduction of public airports might therefore also be associated to the elimination by the Labor government in 1998 of the borrowing restrictions that applied for publicly owned airports.
} 
The main policy implications of our results have been discussed in the previous section and may both add to the debate on the optimal design of the airport industry and provide useful suggestions to inform the regulatory practice. 


\section{References}

Abrate G. and Erbetta F. (2010), "Efficiency and Patterns of Service Mix in Airport Companies: An Input Distance Function Approach", Transportation Research Part E, forthcoming.

Armstrong M., Cowan S. and Vickers J. (1994), Regulatory Reform: Economic Analysis and British Experience. Cambridge, Mass.: MIT Press.

Assaf A. (2009b), "Bootstrapped Scale Efficiency Measures of UK Airports", Journal of Air Transport Management, 1-3.

Barros C. P. and Weber W.L. (2009), "Productivity Growth and Biased Technical Change in UK Airports", Transportation Research Part E, 45, 4, 64.

Barros C.P. and Manage S. (2008), "Productivity Change of UK Airports: 2000-2005", Technical University of Lisbon, Working Paper, 22.

Barros C. P. (2008), "The Technical Efficiency of UK Airports", Journal of Air Transport Management, 14, 175-178.

Bernstein J.I. and Sappington D.M. (1999), "Setting the X-factor in Price Cap Regulation Plans", Journal of Regulatory Economics 16, 5-25.

Bhattacharyya A., Bhattacharyya A. and Mitra K. (1997), "Decomposition of Technological Change and Factor Bias in Indian Power Sector: An Unbalanced Panel Data Approach", Journal of Productivity Analysis, 8, 35-52.

Casarin A. (2007), "Efficient Industry Configurations in downstream Gas Markets. An Empirical Assessment", Energy Economics, 29, 312-328.

Caves D., Christensen L.R. and Swanson J. (1981), "Economic Performance in Regulated and Un-Regulated Environments: A Comparison of Us and Canadian Railroads", Quarterly Journal of Economics, 96, 559-581.

Competition Commission (2008), BAA Market Investigation: Emerging Thinking, London.

Doganis R., Graham A. and Lobbenberg A. (1995), The Economic Performance of European Airports. Department of Air Transport Research Report 3, Cranfield University.

Heckman J.J. (1978), "Dummy Endogenous Variables in a Simultaneous Equation System", Econometrica, 46, 931-960.

Friedlaender A., Berndt E., Wang Chan J. and Vellturo C. (1993), "Rail costs and capital adjustments in a quasi-regulated environment", Journal of Transport Economics and Policy, 27, 2, 131-152.

Hart O. (1983), "The Market Mechanism as an Incentive Scheme", Bell Journal of Economics, $14,366-382$.

Fung M., Wan K., Hui Y. and Law J. (2008), "Productivity Changes in Chinese Airports 19952004", Transportation Research Part E, 44, 521-542.

Littlechild S. (2003), "Reflections on Incentive Regulation", Review of Network Economics, 2, 4, 289-315.

Martin J.C., Roman, C. and Volte-Dorta, R. (2009), "A Stochastic Frontier Analysis to Estimate the Relative Efficiency of Spanish Airports", Journal of Productivity Analysis, 31, 163-176.

Martin J.C. and Socorro M.P. (2009), "A New Era for Airport Regulators Through Capacity Investments" Transportation Research Part A, 43, 6, 618-625.

Newbery D.M. (1999), Privatization, Restructuring and Regulation of Network Utilities, MIT Press.

Niemeier H.M. (2009), "Gateway Airport Investment and Development of Airline Services for a Global Economy", OECD Joint Transport Research Centre, forum 2009, Leipzig.

Office of Fair Trade (2006), UK airports. Report on the market Study and Proposed Decision to 
Make a Market Investigation Reference, London.

Oum T.H. and Fu X., (2008), "Impacts of Airports on Airline Competition: Focus on Airport Performance and Airport-Airline Vertical Relations", OECD Joint Transport Research Centre, Discussion Paper, 17.

Oum T.H., Yan J. and Yu C. (2008), "Ownership Form Matter for Airport Efficiency: A Stochastic Frontier Investigation of Worldwide Airports", Journal of Urban Economics, 64, 422-435.

Parker D. (1999), "The Performance of BAA Before and After Privatization", Journal of Transport Economics and Policy, 33, 3, 133-146.

Pels E., Nijkamp P. and Rietveld P. (2003), "Inefficiencies and Scale Economies of European Airport Operations", Transportation Research Part E, 39, 341-361.

Salazar de la Cruz F. (1999) "A DEA approach to the airport production function", International Journal of Transport Economics, XXVI, 2, 255-70.

Schankerman M., Nadiri M. (1986), "A Test of Static Equilibrium Models and Rates of Return to Quasi-Fixed Factors", Journal of Econometrics, 33, 97-118.

Starkie D. and Thompson D. (1985), Privatizing London's Airports, Institute for Fiscal Studies, Report 16, London.

Starkie D (2001), "A New Deal for Airports?", in Robinson C. (ed.), Regulating Utilities: New Issues New Solutions, IEA, London.

Starkie D. (2008), "The Airport Industry in a Competitive Environment: a United Kingdom Perspective", OECD Joint Transport Research Centre, Discussion Paper, 15.

Sung N., Gorth M. (2000), "Economies of Scale and Natural Monopoly in the US Local Telephone Industry", The Review of Economics and Statistics, 82, 694-697. 


\section{Appendix}

Table 1: Descriptive statistics

\begin{tabular}{|c|c|c|c|c|c|}
\hline & Year & Mean & S.D. & Min & Max \\
\hline \multirow[t]{2}{*}{ W } & 1994 & 12677 & 1517 & 10119 & 16646 \\
\hline & 2005 & 18254 & 2417 & 14359 & 25793 \\
\hline \multirow[t]{2}{*}{$\mathrm{OC}$} & 1994 & 133.2 & 0 & 133.2 & 133.2 \\
\hline & 2005 & 181.3 & 0 & 181.3 & 181.3 \\
\hline \multirow[t]{2}{*}{ pax } & 1994 & 4882 & 11055 & 5.692 & 52000 \\
\hline & 2005 & 8847 & 14706 & 6.115 & 67700 \\
\hline \multirow[t]{2}{*}{ cargo } & 1994 & 71.428 & 216.1 & 0.220 & 1077.4 \\
\hline & 2005 & 101.6 & 283.5 & 0 & 1396.7 \\
\hline \multirow[t]{2}{*}{ wlu } & 1994 & 5596 & 13150 & 8.679 & 63200 \\
\hline & 2005 & 9863 & 17334 & 7.485 & 81626 \\
\hline \multirow[t]{2}{*}{ atm } & 1994 & 58626 & 85863 & 5131 & 413545 \\
\hline & 2005 & 87465 & 103049 & 1548 & 472954 \\
\hline \multirow[t]{2}{*}{ com } & 1994 & 46724 & 122837 & 0 & 588591 \\
\hline & 2005 & 57668 & 130241 & 793 & 638043 \\
\hline \multirow[t]{2}{*}{$\mathrm{k}$} & 1994 & 235844 & 384499 & 1658 & 1394109 \\
\hline & 2005 & 561201 & 1556816 & 6049 & 7789200 \\
\hline \multirow[t]{2}{*}{$\mathrm{Vc}$} & 1994 & 38582 & 78165 & 2178 & 369000 \\
\hline & 2005 & 62594 & 125900 & 4622 & 611800 \\
\hline
\end{tabular}

w: price labour (thousands of GB $£$ )

oc: price other cost (see text)

pax: thousands of passengers

cargo: thousands of tons of cargo and mail

wlu: thousands of work load units (see text)

atm: number of air transport movements

comm: non operational revenue (thousands of GB $£$ )

$\mathrm{k}$ : monetary value of capital stock (thousands of GB $£$ )

vc: variable costs (thousands of GB $£$ )

\section{Table 2 Ownership patterns}

\begin{tabular}{ll}
\hline Heathrow & Priv \\
Gatwick & Priv \\
Stanstead & Priv \\
Southampton & Priv \\
Glasgow & Priv \\
Edinburgh & Priv \\
Aberdeen & Priv \\
Manchester & Pub \\
Bournemouth & Mix (1994); Priv (1995-2000); Pub (2001-05) \\
Humberside & Pub \\
Nott-East Midlands & Priv (1994-2000); Pub (2001-05) \\
Birmingham & Pub (1994-96); Mix (1997-2005) \\
Newcastle & Pub (1994-2000); Mix (2001-05) \\
Belfast & Priv \\
Cardiff & Pub (1994); Priv (1995-2005) \\
Luton & Pub (1994-97); Mix (1998-2005) \\
Blackpool & Pub (1994-2003); Mix (2004-05) \\
Bristol & Pub (1994-97); Mix (1998-2000); Priv (2001-05) \\
Durham & Pub (1994-2002); Priv (2003-05) \\
Exeter & Pub \\
Leeds-Bradford & Pub \\
Liverpool & Priv \\
London City & Priv \\
Norwich & Pub (1994-2003); Mix (2004-05) \\
Southend & Priv \\
\hline
\end{tabular}


Table 3: Variable cost function estimates

\begin{tabular}{|c|c|c|c|c|c|}
\hline & Model 1 & Model 2 & Model 3 & & Model 4 \\
\hline$k$ & $-0.087(3.09)$ & $-0.173(3.87)$ & $-0.067(1.66)$ & $k$ & $-0.095(3.65)$ \\
\hline$w$ & $0.413(54.4)$ & $0.411(51.7)$ & $0.407(25.42)$ & $w$ & $0.412(57.23)$ \\
\hline$w l u$ & $0.340(8.26)$ & $0.361(5.55)$ & $0.617(10.39)$ & $\operatorname{pax}$ & $0.301(8.21)$ \\
\hline com & $0.296(8.81)$ & $0.303(5.85)$ & $0.207(4.50)$ & cargo & $0.020(2.18)$ \\
\hline $\mathrm{atm}$ & $0.294(5.45)$ & $0.351(3.68)$ & $0.050(0.59)$ & com & $0.38(12.21)$ \\
\hline priv & $-0.158(5.77)$ & $-0.171(4.94)$ & $-0.214(7.37)$ & atm & $0.197(3.95)$ \\
\hline$k^{2}$ & $0.202(4.0)$ & $0.213(2.0)$ & $0.192(3.93)$ & priv & $-0.145(5.77)$ \\
\hline$w^{2}$ & $-0.259(3.88)$ & $-0.258(3.64)$ & $-0.278(3.94)$ & $k^{2}$ & $0.223(4.12)$ \\
\hline$w l u^{2}$ & $0.177(4.22)$ & $0.262(3.23)$ & 0.082 (1.93) & $w^{2}$ & $-0.300(4.72)$ \\
\hline $\mathrm{com}^{2}$ & $0.071(11.8)$ & $0.071(6.88)$ & $0.050(7.35)$ & $\operatorname{pax}^{2}$ & $0.139(2.00)$ \\
\hline $\mathrm{atm}^{2}$ & $0.204(3.52)$ & $0.041(0.34)$ & $0.217(4.01)$ & $\operatorname{cargo}^{2}$ & $0.001(0.03)$ \\
\hline$k * w$ & $-0.012(-1.08)$ & $-0.004(0.29)$ & $-0.011(1.03)$ & $\mathrm{com}^{2}$ & 0.088 (10.91) \\
\hline$k * w l u$ & $0.006(0.15)$ & $0.098(1.50)$ & $0.090(2.08)$ & $\mathrm{atm}^{2}$ & $0.472(4.31)$ \\
\hline$k * c o m$ & $0.001(0.05)$ & $0.074(0.71)$ & $-0.028(0.79)$ & $k * w$ & $0.005(0.42)$ \\
\hline$k * a t m$ & $-0.248(-4.31)$ & $-0.499(4.79)$ & $-0.300(5.33)$ & $k^{*}$ cargo & $-0.003(0.23)$ \\
\hline$w * w l u$ & $-0.001(0.06)$ & $-0.001(0.05)$ & $0.001(0.04)$ & $k * \operatorname{pax}$ & $0.040(1.02)$ \\
\hline$w * c o m$ & $0.001(0.39)$ & $-0.006(0.85)$ & $0.001(0.26)$ & $k * c o m$ & $0.031(0.96)$ \\
\hline$w * a t m$ & $0.001(2.67)$ & $-0.001(0.84)$ & $0.001(1.53)$ & $k * a t m$ & $-0.362(4.78)$ \\
\hline com $* w l u$ & $-0.190(3.80)$ & $-0.486(3.95)$ & $0.096(1.85)$ & $w^{*} \operatorname{cargo}$ & $-0.019(4.07)$ \\
\hline$a t m * w l u$ & $0.001(0.01)$ & $-0.001(1.61)$ & $0.001(0.48)$ & $w * p a x$ & $0.005(0.69)$ \\
\hline $\mathrm{atm} * \mathrm{com}$ & $0.205(4.52)$ & $0.700(4.45)$ & $0.133(2.78)$ & $w * c o m$ & $0.004(0.86)$ \\
\hline trend & - & - & $-0.014(1.17)$ & $w * a t m$ & $-0.001(2.95)$ \\
\hline trend $^{2}$ & - & - & $-0.001(0.87)$ & pax $*$ com & $-0.167(3.94)$ \\
\hline trend $* w$ & - & - & $0.001(0.39)$ & $\operatorname{cargo} * \operatorname{comm}$ & $-0.034(2.80)$ \\
\hline trend $* k$ & - & - & $0.002(0.49)$ & $p a x * a t m$ & $-0.040(0.50)$ \\
\hline trend $*$ atm & - & - & $0.025(3.10)$ & cargo*atm & $-0.036(1.88)$ \\
\hline trend $*$ com & - & - & $0.008(1.71)$ & cargo*pax & $0.012(0.98)$ \\
\hline trend $*$ wlu & - & - & $-0.035(5.45)$ & $\mathrm{atm}^{*} \mathrm{comm}$ & $0.0217(4.12)$ \\
\hline
\end{tabular}

Sure Estimates.

Market-year dummies in Model 1,2,3

Market dummies in model 4

$\mathrm{T}$ Statistitics in parenthesis 
Table 4: Variable cost function estimates

\begin{tabular}{lrrr}
\hline & Model 5 & Model 6 & Model 7 \\
\hline$k$ & 3 SLS & SURE & SURE-RE \\
$w$ & $-0.103(3.05)$ & $0.003(0.10)$ & $-0.039(1.09)$ \\
$w l u$ & $0.412(48.0)$ & $0.412(54.3)$ & $0.411(54.5)$ \\
com & $0.314(5.54)$ & $0.237(5.58)$ & $0.260(5.07)$ \\
atm & $0.365(6.43)$ & $0.410(12.41)$ & $0.346(8.40)$ \\
priv & $0.242(4.38)$ & $0.086(1.87)$ & $0.204(3.46)$ \\
$k^{2}$ & $-0.144(1.69)$ & $-0.149(2.31)$ & $-0.114(3.51)$ \\
$w^{2}$ & $0.214(3.45)$ & $0.143(3.10)$ & $0.255(5.31)$ \\
$w l{ }^{2}$ & $-0.171(2.34)$ & $-0.343(5.32)$ & $-0.261(3.98)$ \\
com & $0.156(3.11)$ & $0.067(1.87)$ & $0.114(2.84)$ \\
atm ${ }^{2}$ & $0.199(2.71)$ & $0.064(9.63)$ & $0.066(9.97)$ \\
$k * w$ & $0.123(1.86)$ & $0.154(3.20)$ & $0.164(3.15)$ \\
$k * w l u$ & $0.011(0.79)$ & $-0.011(1.04)$ & $-0.009(0.84)$ \\
$k *$ com & $0.062(1.16)$ & $-0.108(2.94)$ & $-0.108(2.72)$ \\
$k * a t m$ & $-0.028(0.47)$ & $0.014(0.36)$ & $-0.012(0.33)$ \\
$w * w l u$ & $-0.330(4.56)$ & $-0.022(0.46)$ & $-0.071(1.24)$ \\
$w *$ com & $0.002(0.23)$ & $0.003(0.34)$ & $-0.004(0.52)$ \\
$w * a t m$ & $-0.029(2.08)$ & $0.001(0.28)$ & $0.003(0.68)$ \\
com $* w l u$ & $-0.001(0.14)$ & $-0.001(3.67)$ & $-0.001(1.90)$ \\
$a t m * w l u$ & $-0.264(3.68)$ & $0.020(0.40)$ & $-0.084(1.56)$ \\
$a t m *$ com & $-0.001(2.75)$ & $0.001(1.58)$ & $0.001(0.22)$ \\
\hline & $0.355(4.91)$ & $-0.054(1.20)$ & $0.073(1.57)$ \\
\hline
\end{tabular}

Market-year interaction dummies. in all models $\mathrm{T}$ statistics i parenthesis

Table 5: Technical change estimates

\begin{tabular}{llll}
\hline & Full sample & Priv & \multicolumn{1}{c}{ Pub-mix } \\
\hline $1994-95$ & $0.028^{* * *}$ & $0.033^{* * *}$ & 0.020 \\
$1995-96$ & $0.028^{* * *}$ & $0.031^{* * *}$ & $0.024^{* *}$ \\
$1996-97$ & $0.018^{* * *}$ & $0.019^{* *}$ & $0.017^{* *}$ \\
$1997-98$ & $0.015^{* * *}$ & $0.015^{* *}$ & $0.017^{* *}$ \\
$1998-99$ & $0.019^{* * *}$ & $0.017^{* * *}$ & $0.024^{* * *}$ \\
$1999-00$ & $0.020^{* * *}$ & $0.016^{* * *}$ & $0.027^{* * *}$ \\
$2000-01$ & $0.017^{* * *}$ & $0.011^{* * *}$ & $0.026^{* * *}$ \\
$2001-02$ & $0.018^{* * *}$ & $0.010^{* *}$ & $0.031^{* * *}$ \\
$2002-03$ & $0.019^{* * *}$ & 0.010 & $0.034^{* * *}$ \\
$2003-04$ & $0.016^{* *}$ & 0.006 & $0.031^{* * *}$ \\
$2004-05$ & $0.021^{* *}$ & 0.008 & $0.040^{* * *}$ \\
\hline
\end{tabular}

$* * *=\operatorname{sign} 1 \% ; * *=\operatorname{sign} 5 \% ; *=\operatorname{sign} 10$ 
Table 6 Long run scale economies

\begin{tabular}{llllllll}
\hline & Model 1 & Model 2 & Model 3 & Model 4 & Model 5 & Model 6 & Model 7 \\
\hline $10^{\text {th }}$ & $1.88^{* * *}$ & $3.01^{* * *}$ & $1.79^{* * *}$ & $1.71^{* * *}$ & $2.37^{* * *}$ & $1.84^{* * *}$ & $1.89^{* * *}$ \\
$25^{\text {th }}$ & $1.49^{* * *}$ & $1.78^{* * *}$ & $1.53^{* * *}$ & $1.55^{* * *}$ & $1.71^{* * *}$ & $1.59^{* * *}$ & $1.54^{* * *}$ \\
$50^{\text {th }}$ & $1.26^{* * *}$ & $1.38^{* * *}$ & $1.22^{* * *}$ & $1.69^{* * *}$ & $1.34^{* * *}$ & $1.25^{* * *}$ & $1.28^{* * *}$ \\
$75^{\text {th }}$ & $1.06^{* * *}$ & $1.11^{*}$ & $1.10^{* *}$ & $0.96^{* *}$ & $1.06^{* * *}$ & $1.18^{* * *}$ & $1.14^{* *}$ \\
$90^{\text {th }}$ & $0.84^{* * *}$ & $0.64^{* * *}$ & $0.90^{*}$ & $0.74^{* * *}$ & $0.72^{* * *}$ & $1.05^{*}$ & 0.96 \\
\hline
\end{tabular}

$* * *=\operatorname{sign} 1 \% ; * *=\operatorname{sign} 5 \% ; *=\operatorname{sign} 10 \%$. The null hypothesis is that scale economies are constant

Table 7 Short run scale economies

\begin{tabular}{llllllll}
\hline & Model 1 & Model 2 & Model 3 & Model 4 & Model 5 & Model 6 & Model 7 \\
\hline $10^{\text {th }}$ & $1.82^{* * *}$ & $2.77^{* * *}$ & $1.74^{* * *}$ & $1.81^{* * *}$ & $2.49^{* * *}$ & $1.90^{* * *}$ & $1.82^{* * *}$ \\
$25^{\text {th }}$ & $1.44^{* * *}$ & $1.53^{* * *}$ & $1.47^{* * *}$ & $1.52^{* * *}$ & $1.64^{* * *}$ & $1.71^{* * *}$ & $1.47^{* * *}$ \\
$50^{\text {th }}$ & $1.07^{*}$ & $0.98^{* *}$ & $1.15^{* *}$ & $1.11^{*}$ & $1.08^{*}$ & $1.36^{* * *}$ & $1.23^{* * *}$ \\
$75^{\text {th }}$ & $1.03^{* *}$ & $0.97^{* * *}$ & $1.13^{* *}$ & $0.92^{* *}$ & $1.00^{* * *}$ & $1.23^{*}$ & $1.10^{*}$ \\
$90^{\text {th }}$ & 0.91 & $0.67^{* * *}$ & $1.04^{* *}$ & $0.81^{* *}$ & $0.74^{* * *}$ & $1.17^{*}$ & 0.93 \\
\hline
\end{tabular}

$* * *=\operatorname{sign} 1 \% ; * *=\operatorname{sign} 5 \% ; *=\operatorname{sign} 10 \%$. The null hypothesis is that scale economies are constant

Table 8. Long run scale economies: robustness checks

\begin{tabular}{|c|c|c|c|c|c|c|}
\hline & $10^{\text {th }}$ & $25^{\text {th }}$ & $50^{t h}$ & $75^{\text {th }}$ & $90^{\text {th }}$ & $95^{\text {th }}$ \\
\hline atm & $1.83^{* * *}$ & $1.39^{* * *}$ & $1.16^{* * *}$ & 1.05 & $0.84^{* * *}$ & $0.79^{* * *}$ \\
\hline wlu & $1.72^{* * *}$ & $1.40^{* * *}$ & $1.24^{* * *}$ & $1.08^{* *}$ & $0.86^{* *}$ & $0.79^{* * *}$ \\
\hline \multirow[t]{2}{*}{ pax } & $3.13^{* * * *}$ & $1.54^{* * * *}$ & $1.50^{* * *}$ & 1.00 & $0.92 *$ & $0.82^{* * *}$ \\
\hline & small & & medium & & large & \\
\hline atm & $1.66^{* * *}$ & & $1.12^{* * *}$ & & $0.82^{* * *}$ & \\
\hline wlu & $1.67^{* * *}$ & & $1.14^{* * *}$ & & $0.82^{* * *}$ & \\
\hline pax & $1.67^{* * *}$ & & $1.15^{* * *}$ & & $0.82^{* * *}$ & \\
\hline
\end{tabular}

$* * *=\operatorname{sign} 1 \% ; * *=\operatorname{sign} 5 \% ; *=\operatorname{sign} 10 \%$. The null hypothesis is that scale economies are constant Estimates for atm and $w l u$ from Model 1; estimates for pax from Model 4 
DEPARTMENT OF ECONOMICS AND PUBLIC FINANCE "G. PRATO" UNIVERSITY OF TORINO

Corso Unione Sovietica 218 bis - 10134 Torino (ITALY)

Phone: +390116706128 - Fax: +390116706062

Web page: http://eco83.econ.unito.it/prato/ 